\title{
Biliocolonic Fistula Through Cystic Duct Remnant
}

\author{
Syed Muzamil Andrabi M.S., ' Javaid Ahmad Bhat M.S., ${ }^{2}$ Mohd Yousuf Dar M.S., ${ }^{3}$ \\ MubashirAhmad Shah M.S. ${ }^{4}$ \\ ${ }^{1,2,3}$ Senior Residents, ${ }^{4}$ Additional Professor \\ Department of General and Minimal Invasive Surgery
}

\section{A B S T RA C T}

Cystic duct remnant-colonic fistula is a rare entity. Only a few cases have been reported in the literature. They usually arise after open or laproscopic cholecystectomy for gall stone diseases. Other causes may include malignancies and inflammatory bowel diseases. We are presenting a case of bilioenteric fistula involving cystic duct remnant and transverse colon in a female patient who had undergone open cholecystectomy five years before. JMS 2018:21 (2):120-121

Keywords: Cholecystectomy, Cystic duct stump, Fistula, Colon

\section{Case Report}

47 years old lady presented with pain right upper abdomen and yellowish discoloration of eyes of one year duration. She had undergone open cholecystectomy 5 years back. Liver function tests of the patient showed obstructive pattern of jaundice with normal coagulogram and blood counts. Transabdominal ultrasonography revealed dilated intrahepatic biliary radicles (IHBR) with evidence of diffuse pneumobillia. Common bile duct (CBD) appeared dilated and contained $1.9 \times 2.2 \mathrm{~cm}$ mixed echogenicity area near the lower end suggestive of soft calculus with debris. MRCP revealed dilated IHBR with pneumobilia, with CBD containing $23 \mathrm{~mm}$ calculus in its middle region with some debris. Patient underwent ERCP that showed Cystic duct stump calculus compressing Common Hepathic Duct (CHD). The stone couldn't be retrieved because of its large size and relatively nondilated lower end. Papillotomy was done and a plastic stent was deployed for endobiliary drainage. Patient was subsequently taken for open biliary exploration. During surgery she was found to have a communication between biliary tree and transverse colon through a cystic duct remanant. Cystic duct remnant was

\section{Correspondence}

Dr. Syed Muzamil Andrabi

Senior Resident,

Department of General Surgery SKIMS, Srinagar Email: syedmiaz67@gmail.com excised. Transverse colon was repaired primarily. CBD was explored; stone, debris and biliary stent were retrieved. CBD was repaired over a T-tube which was removed after 4 weeks.

\section{DISCUSSION}

Bilioenteric fistulae are rarely encountered in surgical practice. Only a small number of cases have been reported till date. Abiad F et al reported biliary-colonic fistula through a cystic duct stump in a patient who had undergone laproscopic cholecystectomy in the past. ${ }^{[1]}$ Munene $\mathrm{G}$ et al described biliary colonic fistula in a patient after open cholecystectomy. ${ }^{[2]}$ Another case of biliary-colonic fistula fallowing cholecystectomy with iatrogenic biliary injury was reported by Macedo FI et al. The fistulus tract existed between the CHD and large bowel. ${ }^{[3]}$ Ramos-De Ia Medina A et al described two cases of cholecysto-colonic fistulae, one in the context of cholelithiasis and the other secondary to adenocarcinoma of gallbladder. ${ }^{[4]}$ Chander VP et al also reported a case of choledocho-colonic fistula through a cystic duct stump secondary to distal CBD stricture. ${ }^{[5]}$ Another case of cystic duct remnant fistulisation to the gastrointestinal tract was described by Woods MS et al. ${ }^{[6]}$ The authors emphasized on ERCP as diagnostic and potentially therapeutic modality of choice. If the endoscopy fails, operative therapy is indicated, including division of fistula, excision of cystic duct remnant and CBD 


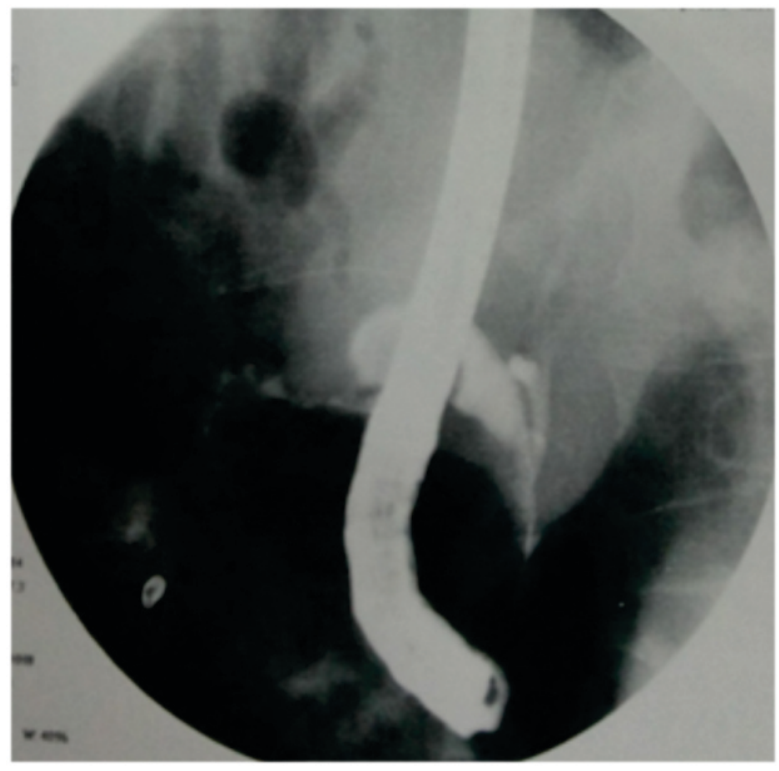

ERCP image showing cystic duct stump stone.

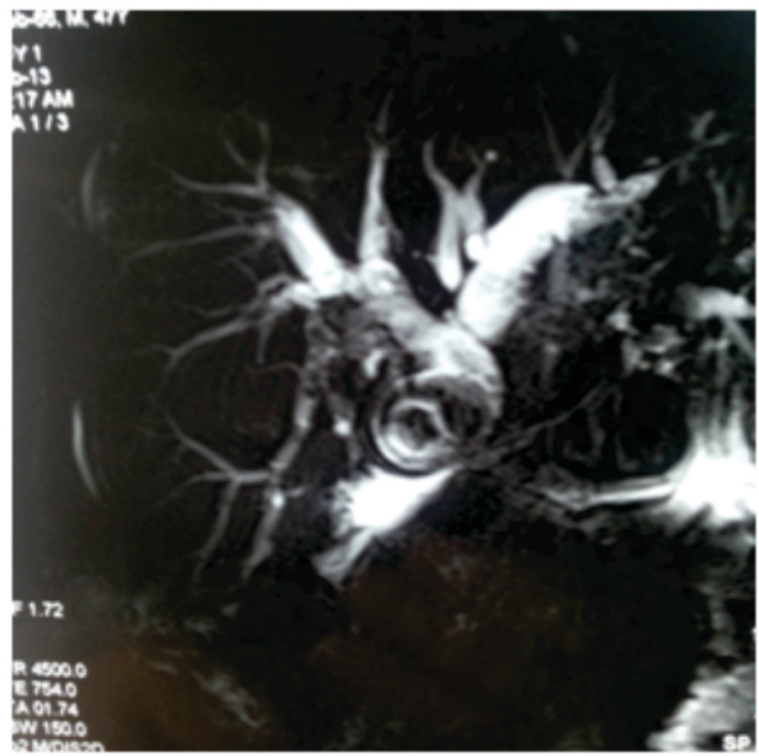

MRCP showing dilated IHBR with pneumobilia with CBD stone

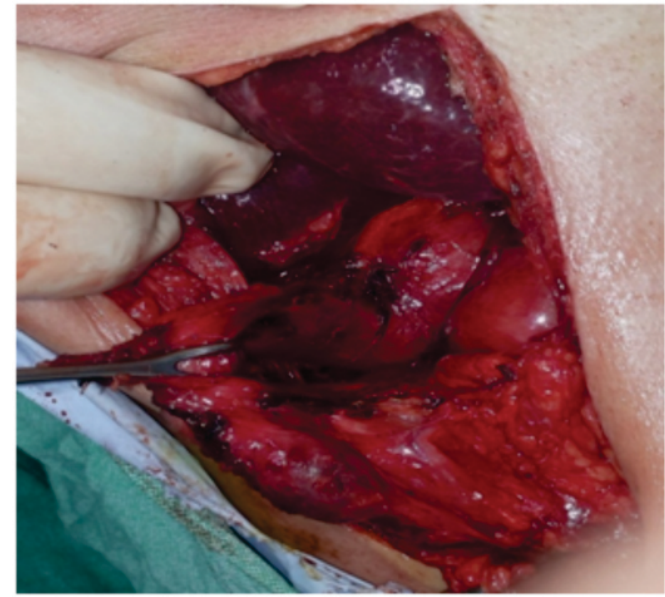

Intraoperative image demonstrating Cystic duct stump as communication between dilated CBD and transverse colon.

exploration. $^{[6]}$

\section{REFERENCES}

1. Abiad F et al. Biliary-colonic fistula through a cystic duct stump. Int Surg. 2000 Jul-Sep; 85(3): 231-3.

2. Munene $\mathrm{G}$ et al. Biliary-colonic fistula: a case report and literature review. Am Surg. 2006 Apr; 72(4): 34750 .

3. Macedo FI et al. Biliary-colonic fistula caused by cholecystectomy bile duct injury. Hepatobiliary Pancreat Dis Int. 2013 Aug; 12(4): 443-5.
4. Ramos-De Ia Medina A et al. Biliary-colonic fistulas. Analysis of 2 cases and literature review. Rev Gastroenterol Mex. 2002 Jul-Sep; 67(3): 207-9.

5. Chander VP et al. Choledochocolonic fistula through a cystic duct remanant. A case report. Am J Gastroenterol. 1980 Aug; 74(2): 179-81

6. Woods MS et al. Cystic duct remnant fistulization to the gastrointestinal tract. Surgery. 1992 Jan; 111(1): $101-4$. 